\title{
Do visível ao visual: poderes do blecaute na Magie Nouvelle ${ }^{1}$
}

\author{
From the visible to the visual: powers of the \\ blackout in the Magie Nouvelle
}

Véronique Perruchon ${ }^{2}$ Tradutora: Nadia Moroz Luciani ${ }^{3}$ 


\section{Resumo}

Esse artigo se debruça sobre uma recontextualização do uso do blecaute na história da magia. Faz também apontamentos históricos da relação entre a magia e a luz e discute ainda a relação entre o blecaute e a obscuridade como condições espetaculares do efeito mágico e da experiência sensorial do espectador. Por fim, apresenta as modalidades e os desafios contemporâneos próprios à arte ilusionista que caracteriza a Magie Nouvelle.

Palavras-chaves: blecaute; magia; iluminação cênica; Magie Nouvelle; percepção

\section{Abstract}

This article looks at a recontextualization of the use of blackout in the history of magic. It makes historical remarks between magic and light and also discusses the relationship between blackout and obscurity as spectacular conditions for the magical effect and the spectator's sensorial experience. Finally, it presents the contemporary challenges and modalities of the illusionist art that characterizes the Magie Nouvelle.

Keywords: blackout; magic; lighting design; Magie Nouvelle; perception

E-ISSN: 2358.6958

\footnotetext{
1 Texto originalmente publicado no livro "Machines. Magie. Médias. de Frank Kessler, Jean-Marc Larrue e Giusy Pisano (Orgs.). Villeneuve D’Ascq: Presses Universitaires du Septentrion, 2018. p. 151-160. 2 Doutora em Estudos Teatrais pela Universidade Sorbonne Nouvelle Paris 3, Professora de Estética do teatro e lluminação cênica e Coordenadora do grupo de
pesquisa LdS - Lumière de Spectacle do CEAC na Universidade de Lille, na França. veronique.perruchon@univ-lille.fr

3 Iluminadora, Doutoranda em Artes Cênicas - PPGAC da ECA-USP, Professora de lluminação Cênica e Coordenadora do Projeto de Extensão LABIC na Faculdade de Artes do Paraná - Campus de Curitiba II da UNESPAR - Universidade Estadual do Paraná. nadia.luciani@unespar.edu.br 
A Magie Nouvelle ${ }^{4}$ é uma arte ilusionista, da qual algumas variações cênicas se apoiam em ilusões de ótica e na perturbação das referências. O blecaute trazido à sua cena oferece um ambiente propício para revelar as aparições mais irreais: os corpos no palco, livres das restrições do real, provocam o encontro com o sentimento mágico. Através de uma experiência sensorial, o espectador mergulha em um universo irracional e cativante que tem o poder evocatório da imagem aberta (Georges Didi-Huberman). O blecaute imersivo tem a faculdade de transformar a opacidade da tela do visível até adquirir as qualidades do visual. Espetáculos como Vibrations (2010) e Notte (Cia 14:20) ou ainda Les Limbes (Cia Mosntre[s], 2014) permitirão demonstrar suas ocorrências. No entanto, se essa abordagem mágica do blecaute parece das mais novas, sua mobilização marcou a história da magia. Esse artigo vai se debruçar, portanto, num primeiro momento, sobre uma recontextualização do uso do blecaute na história da magia, antes de apresentar as modalidades e os desafios contemporâneos próprios à Magie Nouvelle.

\section{Apontamentos históricos da relação entre magia e luz}

Normalmente, o termo mágico é usado para qualificar um fenômeno incrível e realizado sem efeitos especiais, ou melhor, sem ajuda humana, é mágico, dizemos. No campo específico da magia espetacular, essa acepção está relacionada ao pacto espectatorial segundo o qual o mágico vai mostrar tudo ao espectador e este, corolariamente, vai ver tudo. O que é esclarecido pelo título, tão explícito quanto sedutor, de uma das primeiras obras de popularização da arte dos mágicos: A Magia branca revelada ou Explicação de números [...], de 17845. Essa curiosidade acompanha o desejo de saber ao qual o teatro e os espetáculos se adaptaram. O grande prazer do espectador até o final do século XVIII era assistir às trocas de cenário às vistas do publico. Gostamos de entender e ver os mecanismos, mas também de sonhar: ser suspendido entre a razão e o encantamento dos sentidos. Já Fontenelle, algumas décadas antes, em 1686, inscreveu seus Diálogos sobre a pluralidade dos mundos nessa ambivalência: "queremos saber mais do que vemos"6 colocando a libido sciendi de Pascal sob o selo do desejo proibido. Ver, e mais ainda, desejar ver, demonstra não apenas uma mera curiosidade intelectual, mas o prazer da transgressão ${ }^{7}$. Fontenelle se entusiasma ainda com metáfora do espetáculo: "eu sempre imagino, diz ele, que a natureza é um grande espetáculo que se assemelha ao da Ópera. Do lugar em que a senhora está na Ópera, a senhora não vê o teatro exatamente como ele é; os cenários e as máquinas foram dispostos de forma a produzir um efeito agradável de longe, e se esconde das suas vistas essas rodas e esses contrapesos que fazem todos os mo-

\footnotetext{
${ }^{4}$ Marca criada por Raphaël Navarro, Clément Debailleuil et Valentine Losseau.

5 Henri Decremps, La magie blanche dévoilée ou explication des tours, Paris, Langlois, 1784. Notar a presença do particípio passado do verbo « revelar » associado à magia « branca «, supondo ao mesmo tempo a presença de um véu e de uma magia não branca, o que a continuação do artigo abordará.

${ }^{6}$ Bernard Le Bouyer de Fontanelle, Entretiens sur la pluralité des mondes, coll. GF - Littérature et civilisation, Paris, Flammarion, 1998 [1686], p. 62. - Obra traduzida para o português por Denise Bottmann e publicada pela Editora da UNICAMP em 2013. (Nota da tradutora)

7 Em 1986, quando da primeira publicação do Diálogos, os jansenistas haviam reativado uma tradição cristã, conduzindo ao pecado da vaidade o desejo de conhecer. Remanescia do pecado original, segundo o qual Adão e Eva comeram o fruto da árvore da ciência do bem e do mal, uma árvore que era agradável à visão e abriu-lhes os olhos, aos dois, fazendo-os ver sua nudez. Ibid.
} 
vimentos ${ }^{8 "}$. Mas Fontenelle propõe à sua interlocutora, a Marquesa, de compartilhar um outro prazer, o de ver o outro lado ou os bastidores do teatro: "a senhora está tão disposta a entrar em tudo isso que eu quero lhe dizer, que eu acredito que devo apenas puxar a cortina e lhe mostrar o mundo9". Tendência que irá se amplificando, visto que conhecer será, sem dúvida, a palavra-chave do, apropriadamente chamado, Século das Luzes. O século XIX é, então, a época dos mágicos técnicos, científicos, demonstradores de fenômenos físicos, que participam da popularização científica de maneira lúdica. É o tempo dos cientistas ilusionistas ou escamoteadores, que exibiam a ciência em barracas de feira por meio de personagens populares célebres, como La Femme Torpille ou L'Homme Accumulateur ${ }^{10}$. O gênero se desenvolve e seu sucesso leva Jean-Eugène Robert-Houdin (1805-1871) a fazer construir, em 1845, em pleno coração de Paris, no Palais Royal, um teatro especialmente equipado para a magia, no qual ele realizava tanto aparições e desaparecimentos quanto os efeitos da eletricidade em suas Noites Fantásticas. Para além da física divertida, a magia se inscreve, então, no campo do visível e entra no século XX por um jogo entre opacidade e transparência, no qual a ilusão reside sob o princípio de uma falsa cumplicidade: o mágico finge mostrar tudo, como demonstram os cartazes dos grandes shows do mágico americano Howard Thurston ${ }^{11}$. Essa variação da magia como campo do visível é reforçada, em prestidigitação, pelo uso de luvas brancas e do arregaçar das mangas agitando os dedos de maneira fluída como prova da falta de trucagem. A magia se faz em plena luz, no sentido próprio e figurado, e é sobre essa pseudo-cumplicidade com o espectador que se apoia a atmosfera dos números.

A tendência aumentará no decorrer do século XX, adicionando brilhos e lantejoulas ao mundo da magia, a ponto de se tornar sua marca, que encontramos na classificação dos números de magia. Só é necessário consultar o índice da obra de Max Dif, História llustrada da prestidigitação ${ }^{12}$ ou a de Maurice Saltano, Os Mágicos: o mundo fantástico do ilusionismo ${ }^{13}$ para se convencer: capítulo 1 . Aparições e desaparecimentos, capítulo 2. O Dinheiro e o último capítulo, ao mesmo tempo explícito e sugestivo, Antes de apagar os refletores..., que atesta a presença da luz geral. O dinheiro é um assunto e uma temática estética amplamente usada em magia, em especial por Howard Thurston em seu show $O$ mistério de um milhão de dólares ${ }^{14}$,

\footnotetext{
8 Ibid., p.64 sq

Tradução feita pela tradutora, podendo não corresponder à realizada por Denise Bottmann, já editada em português. (Nota da tradutora)

9 Ibid. Idem

${ }_{10}$ Personagens criados por artistas do século XIX na Franca, que se apresentavam em feiras públicas com demonstrações de fenômenos da eletricidade: La Femme Torpille com a eletrostática em seus cabelos e L'Homme Accumulador mostrando como podia conduzir a eletricidade. (Nota da tradutora)

11 Ver, na presente obra, o texto de Jacques Ayroles e Giusy Pisano.

A autora se refere aqui a outro artigo do mesmo livro em este foi originalmente publicado: Machines. Magie. Médias. de Frank Kessler, Jean-Marc Larrue e Giusy Pisano (Orgs.). Villeneuve D'Ascq: Presses Universitaires du Septentrion, 2018. (Nota da tradutora)

${ }_{12}$ Max Dif, Histoire illustrée de la prestidigitation, Paris, Maloine, 1986. Ver também: Max Dif, Histoire et Évolution des techniques dela prestidigitation, Paris, ed. pelo autor, copyright Maxime Roux, 1971-1973, 3 volumes.

${ }^{13}$ Bernard Joubert e Maurice Saltano, Les Magiciens : le monde fantastique de lillusionisme, Paris, Syros/Alternatives, 1990.

${ }^{14}$ Ver, na presente obra, o texto de Jacques Ayroles e Giusy Pisano.

A autora se refere aqui a outro artigo do mesmo livro em este foi originalmente publicado: Machines. Magie. Médias. de Frank Kessler, Jean-Marc Larrue e Giusy Pisano (Orgs.). Villeneuve D'Ascq: Presses Universitaires du Septentrion, 2018. (Nota da tradutora)
} 
que incorporava, em 1929, o sonho de uma riqueza impossível, pelos paetês que são associados a ela. A magia encontra, então, o mundo das fadas e seu universo cintilante, que percebemos no imaginário popular e dos desenhos animados de Walt Disney desde Fantasia (1940), no qual Mickey vive O Aprendiz de Feiticeiro ${ }^{15}$. De maneira geral, tanto nos Estados Unidos quanto na Europa, o poder das fadas está associado a um jato de pó mágico brilhante. A associação da magia com o mundo das fadas pode ser vista em palcos e shows de televisão, como os de Maurice Saltano e Monique Dorian, que formam uma dupla de estrelas internacionais do music-hall e da magia dos anos 1950 e 1960. Essa fascinação não é nova, como evidenciado pelo tema, tanto nos contos populares quanto nos mundos das fadas teatrais, onde os poderes mágicos podem trazer, há séculos ${ }^{16}$, riqueza, dinheiro e pedras preciosas ${ }^{17}$. Mesmo que a diferença primordial resida no fato de que o espectador de magia assiste a prodígios maravilhosos e que o do teatro adere a uma ilusão com conhecimento de causa, os procedimentos para conduzir o espectador ao universo do maravilhamento e da ilusão das fadas são os mesmos, atuando com o poder do fascínio. A partir daí, para associar magia à poesia, há apenas um passo, como evidenciado pelo capítulo $A$ Poesia do livro de Maurice Saltano, já citado, no qual o autor designa a magia como uma "beleza surreal, um mundo de perfeição, leve, macio e luminoso ${ }^{18 " . ~ A ~ d u p l a ~ m a g i a ~ e ~}$ maravilha se reencontra na associação da luz e do maravilhamento, cuja origem espetacular remonta aos Prazeres da Ilha Encantada, em Versalhes em $1664^{19}$. O encantamento poético associado ao esplendor luminoso permite a Luís XIV literalmente ofuscar seus cortesãos ${ }^{20}$.

No campo da magia, se a luz está associada às diferentes variações temáticas (conhecimento, conivência, poder, dinheiro, maravilhamento, mundo das fadas, poesia), ela é também, e provavelmente acima de tudo, uma necessidade técnica. Ofuscar o espectador, atrair seu olhar pela misdirectio ${ }^{21}$, criando áreas iluminadas, são processos que se apoiam em aspectos técnicos, como os cenários com cortinas cintilantes e a roupa de paetê que molda o corpo da assistente, pronta para desaparecer, aos quais se associam outros procedimentos técnicos, como os figurinos com mangas, as capas e a cartola do mágico. É assim que, descrevendo as particularidades técnicas, todo um conjunto de figuras e do imaginário da magia foram sendo constituídos por meio de uma dramaturgia própria à magia branca, magia da luz geral e dos paetês.

\footnotetext{
${ }_{15}$ Antes de ser uma sequencia do longa-metragem Fantasia (1940), O Aprendiz de Feiticeiro foi primeiro um curta-metragem dos estúdios Disney em 1937, cuja trama se inspirou no poema de Goethe de 1797 e sua composição musical por Paul Ducas em 1897.

${ }_{16}$ Jean de La Fontaine, La Poule aux œufs d'or, em Fábulas, livro V, 1668, e as variações do tema em contos, como os de Francis Lacassin (ed.), Si les fées m'étaient contées... 140 contes de fées de Charles Perrault à Jean Cocteau, Paris, Omnibus, 2003.

17 Ver, na presente obra, o texto de Lisa Jankovic.

A autora se refere aqui a outro artigo do mesmo livro em este foi originalmente publicado: Machines. Magie. Médias. de Frank Kessler, Jean-Marc Larrue e Giusy Pisano (Orgs.). Villeneuve D’Ascq: Presses Universitaires du Septentrion, 2018. (Nota da tradutora)

${ }^{18}$ Bernard Joubert e Maurice Saltano, op,cit.

${ }_{19}$ Festas herdadas de balés da corte e outras festas privadas das quais a mais conhecida: O Ballet cômico da rainha, de Balthasar de Beaujoyeulx, apresentada em 1581 para a inauguração da Sala do Petit Bourbon. Esta festa inaugura, na França, o princípio das encenações luxuosas, com maquinários, cenários, luzes e fogos de artifício cujo libreto dá uma descrição cênica na qual a exibição suntuosa é dada pela abundância de sinais de riqueza.

${ }^{20}$ Ver Véronique Perruchon, Luz e poder, in Noir : lumière et théatralité. Villeneuve-d’Ascq: Presses Universitaires du Septentrion, 2016, p.34-40.

21 Termo que exprime, segundo a autora, o efeito de conduzir a atenção do espectador para um ponto luminoso do palco. (Nota da tradutora).
} 


\section{Blecaute e obscuridade como condições espetaculares do efeito mágico}

Em contraste, outro universo se constituiu, historica e paralelamente, aquele da magia do mistério e dos campos ocultos. Essa magia negra, associada ao prazer do medo, é relativa ao campo do invisível, que atravessou os séculos desde as Fantasmagorias de Etienne-Gaspard Robertson. Fora dos teatros, as Fantasmagorias, herdeiras da lanterne magique ${ }^{22}$ não apenas exigiam o blecaute na sala, mas também atuavam com ele para criar uma atmosfera propícia à ansiedade gerada no espectador pelas aparições. Nas suas Memórias, Robertson (1764-1837), que se dedica mais às anedotas e circunstâncias de suas viagens de aeronauta do que à explicação de suas Fantasmagorias, conta ainda uma situação que confirma esse caso: "um dia, de fato, em que a plateia estava lotada e que o público, composto pela elite da sociedade, aguardava, em uma completa escuridão, emoções de sepulturas e fantasmas, um grito repentino fez todo mundo estremecer ${ }^{23 " . ~ N o ~ t e a t r o, ~ e s t a ~ e ́ ~ a ~ e ́ p o c a ~ d a ~ l u z ~ g e r a l, ~ e x c e t o ~ p a r a ~}$ os efeitos meteorológicos ou especiais. Apenas os teatros ópticos necessitavam do blecaute.

Em relação aos fenômenos de aparição, o ambiente do blecaute é uma necessidade técnica. Acontece o mesmo com os espetáculos realizados no blecaute para revelarem certos elementos por fluorescência. O princípio é antigo. No século XIX, em um balé apresentado na Gaîté, intitulado Os Quatro Elementos (1834), efeitos de aparição e de desaparecimento eram feitos pelo jogo de contraste entre o branco e o preto: os bailarinos, "esqueletos cujos ossos foram desenhados em uma malha justa, em branco sobre fundo preto", moviam-se na penumbra, "a luz foi diminuída e restava apenas uma vaga luminosidade para ver o balé". E de tempos em tempos, quando "eles viravam de costas; sem ter nenhum desenho atrás das malhas, eles desapareciam completamente no fundo preto uniforme sobre o qual não se destacavam mais"24. O efeito produzido revela prodígio e escamotagem, da mesma forma que os efeitos dos primeiros filmes de Méliès, que pretendiam uma demonstração de transformações mágicas e eram feitos baseados neste princípio de teatro negro ao invés de montagem ou edição. Foi o mágico e diretor alemão Ben Ali Bey, criador do teatro negro (black art) em 1885, um espetáculo inteiramente dedicado aos efeitos mágicos no blecaute. Na década de 1920, o teatro negro foi desenvolvido por Oskar Schlemmer na Bauhaus com La Dance des bâtons (1926). Essa técnica é, então, perpetuada em Praga na década de 1950, com o uso de luzes ultravioletas, em uma mistura de teatro tradicional, pantomima e balé, na qual os objetos e corpos se destacam de um fundo negro, favorecendo uma visão sobrenatural, mas que depois a industrialização do espetáculo retomou para os circuitos turísticos. O princípio, independentemente de questões estéticas de bom ou mau gosto, reside no fato de que

\footnotetext{
${ }^{22}$ Dispositivo ancestral dos projetores de vídeo utilizado na Europa desde o início do século XIX. (Nota da tradutora)

${ }^{23}$ Étienn-Gaspard Robertson (Étienne-Gaspard Robert era seu verdadeiro nome), Mémories récréatifs, scientifiques et anecdotiques du physicien-aéronaute E. G. Robertson, v. II, Paris, Rignoux, 1833, p.177

${ }^{24}$ Ludovic Celler, Os Cenários, os Figurinos e a Encenação no século XVII, 1615-1680, Paris, Liepmannsshohn \& Dufur, 1869 , p.14.
} 
o palco é totalmente preto, bem como os figurinos dos atores invisíveis, enquanto os objetos e adereços manipulados se destacam em cores vivas, para criar efeitos visuais espetaculares. O princípio, chamado de luz negra, permite destacar as cores no blecaute com uma impressão de fluorescência, visto que são iluminadas apenas por uma parte do espectro luminoso ${ }^{25}$. Esse teatro negro exige a escuridão absoluta da sala, além de um dispositivo totalmente preto; os elementos de cor branca se destacam de uma maneira singular, não natural e parecem ganhar vida sozinhos, planar e voar, aparecer e desaparecer como que por magia. É um processo tecnicamente diferente daquele outro tipo de luz negra baseada no uso de ultravioleta. Foram os Ballets Loïe Fuller (dez anos após sua morte) que trouxeram seu uso cênico em 1938, durante um balé na sala Pleyel, realizado na luz negra. Tecnicamente, a luz negra combina o uso de lâmpadas especiais, sejam lâmpadas equipadas com vidro Wood ${ }^{26}$ que permitem filtrar apenas os raios ultravioleta (quase radiações) ou lâmpadas tubulares fluorescentes (geralmente chamadas, erroneamente, de néons), e um suporte branco cuja fluorescência será tornada visível pelas lâmpadas apropriadas. Quaisquer que sejam os processos usados para fazer acontecer uma aparição, o blecaute se trona um suporte plástico e de ambientação, mas também uma maneira de dar ao corpo desaparecido, mas imaginado, um peso e uma dinâmica fornecidos pela gravitação e pela massa de sua corporalidade. O teatro negro, nesse sentido, torna-se um caso em que o espectador tem uma experiência sensorial por procuração. A ausência de peso parece ser possível, como nos shows de Philippe Genty, nos quais os personagens flutuam no ar entre os planetas. Tanto artista visual quanto um pouco mágico, Philippe Genty trabalha com a matéria poética que envolve as perturbações espaço-temporais. No entanto, do ponto de vista técnico, ele não usa a luz negra, mas um corredor (cruzado) de luz cujas definições técnicas foram precisamente definidas por seu iluminador, Pascal Laafili. O princípio lhe permite iluminar os diferentes objetos em cena sem revelar os procedimentos, o que lhes confere uma consistência mais realista, convidando ao sonho. O blecaute circundante permite executar esse processo cenicamente.

O princípio mágico repousa, tradicionalmente, na inclusão do espectador, que se torna partícipe, fiador e garantia do efeito: ele é conivente e consente com a veracidade dos fatos e a ausência de trucagens, o que incorpora a estética dos espetáculos de magia e de prestidigitação apresentados sob luz plena. No entanto, o princípio mágico também pode repousar sobre uma outra forma de inclusão do espectador, que não está mais conivente com o mágico para consentir com a veracidade dos fatos ou a ausência de trucagens, mas para constatar os poderes, que escapam tanto ao espectador quanto ao mágico. 0 mágico se torna uma espécie de médium entre um fenômeno inexplicável e o público. De um ponto de vista estético e técnico, pode-se traçar, por essas duas orientações, uma nova apreciação da oposição entre a Magia Branca (em plena luz) e a Magia Negra (no escuro), ou seja, entre o visível e o invisível. Também poderíamos relacionar essas oposições às de duas formas teatrais

\footnotetext{
${ }^{25}$ A luz negra, cujo comprimento de onda se situa entre 405 e 375 nanômetros (entre o violeta e o ultravioleta), nega ao olho a percepção das outras cores, 0 que provoca o efeito de luminescência.

${ }^{26}$ Marca especial de vidro com revestimento especial, rico em óxido de níquel e de ferro, usado na fabricação das lâmpadas de luz negra. (Nota da tradutora)
} 
espetaculares que surgiram durante o século XIX: por um lado, o teatro de cabaré, no qual o prazer lúdico e a abordagem social estão associados aos da saída, do programa; e por outro lado, o teatro de arte, de vanguarda, que exige uma mudança no comportamento do espectador, que se entrega a uma forma de interiorização do prazer estético. Exterioridade versus interioridade, da mesma forma que tiveram dois protocolos espetaculares na magia: luz versus escuridão.

\section{Magie Nouvelle, do visível ao visual: Realizar o imaginário do artista}

A Magie Nouvelle, corrente da qual Raphael Navarrao é um dos fundadores, assim como porta-voz, é uma arte ilusionista, cujo interesse reside na dramaturgia cênica. Os espetáculos da Magie Nouvelle, baseados em ilusões de ótica e na perturbação das referências, têm como desafio a deturpação do real, bem entendido que o real é o material de base da Magie Nouvelle, como o movimento o é para a dança, o som para a música, a cor para a pintura, etc. A questão fundamental colocada pelos espectadores da Magie Nouvelle é, portanto, a manipulação desse novo material.

Na Magie Nouvelle, a magia não tem um fim em si mesma, ela não pode existir se não for a serviço de um propósito cênico. Corolariamente, a figura do mágico pode desaparecer ou se transformar em personagem. É o caso de Étienne Saglio em La Nuit des Monstres e de Yann Frisch em La Syndrome de Cassandre, espetáculo no cruzamento entre o ilusionismo, o teatro de objetos, de marionetes e de clown. Este princípio pode também gerar produções mágicas sem mágico. Quando Clément Debailleul colabora com as companhias Pentimento (/dentités numériques, 2008), Vivre dans le Feu e Louise Levêque (Plus Loin, 2014) ou com seu irmão pintor Louis Debailleul (Horizons, 2012) para realizar instalações ou performances plásticas, as criações desses especialistas em dados digitais, incorporam a ideia de que a magia possa viver e existir sem necessariamente passar pelo mágico, os meios tecnológicos podendo, segundo ele, ser considerados como os parceiros essenciais para a criação do sentimento mágico em contextos não mágicos a priori: "na ilusão própria da pintura, a superfície se abre, a profundidade emerge, a cor se ilumina. Um movimento surdo, implícito acaba de nascer ${ }^{27 "}$.

A palavra-chave da Magie Nouvelle é a dramaturgia. A corrente dá a si mesma o objetivo de realizar o imaginário do artista e cada espetáculo é dotado de uma dramaturgia específica que mobiliza todos os componentes artísticos. Assim é com a luz, da qual Elsa Revol é a criadora principal. Seu trabalho faz parte de um projeto no qual se articulam o prazer do espetáculo e a realização do objetivo do artista, qualquer que seja a luminosidade necessária, da luz plena à obscuridade, de modo a criar uma visibilidade ou uma invisibilidade. Desta forma, Baltasse, de Yann Frisch, demanda luz plena, enquanto Les Limbes, de Etienne Saglio, necessita da obscuridade. A Magie Nouvelle não se limita a realizar espetáculos que necessitam da obscuridade. No entanto, o pacto espectatorial da Magie Nouvelle não está mais na estética do visível para mostrar tudo; o pacto do espectador não reside mais sobre o critério da

${ }_{27}$ Théâtre Auditorium Poitiers (6 de julho de 2011), Vibrations | Entrevista de Clément Debailleul [Vídeo disponível na internet], https://vimeo.com/26060991. 
conivência do endossamento do efeito mágico, mas na aceitação da transformação do real. $O$ real repousando sobre referências culturais (crenças), a percepção dos cinco sentidos (visão prioritária), a cognição (reconstituição cognitiva do real perturbado ou recuperação pelo cérebro das informações reconstruídas). Certamente, esse novo pacto se baseia noutro, bem conhecido na literatura, da suspensão consentida de incredulidade ${ }^{28}$, mas essa adesão comum entre o tempo de um espetáculo em torno de uma outra realidade ou de uma realidade modificada e transformada que leva a uma escala maior do que aquela compartilhada por toda comunidade através de sua cultura ${ }^{29}$. O blecaute é, antes de tudo, um meio propício para permitir que o espectador penetre nessa realidade modificada.

\section{O blecaute e a Magie Nouvelle}

O blecaute não é nada, ele não é nem invisível, nem inconsistente, ele é. Não é porque, no blecaute, não há nada para ver, que o blecaute signifique que ele não é nada. Não há nada para ver, mas nós vemos o blecaute. O blecaute não está do lado do invisível. Ele tampouco é ilusão de percepção: ele pode provocá-la, mas não é uma ilusão. Porque se "a ilusão de percepção", nos lembra Clément Rosset, "alia a invisibilidade à inconsistência ${ }^{30 ", ~ e s s e ~ n a ̃ o ~ e ́ ~ o ~ c a s o ~ d o ~ b l e c a u t e . ~ P o r ~ o u t r o ~ l a d o, ~ o ~ b l e c a u t e ~}$ é neutro. Se ele é carregado de um sentido ou de uma expressividade, é bem porque projetamos os nossos sentidos sobre ele. Toda a arte da Magie Nouvelle se sustenta nessa magia: fazer ver o blecaute tirando-o de sua neutralidade, como um signo ou uma abstração. Ele entra em uma construção que repousa sobre a alteridade, como foi demonstrado por Pierre Soulages no contato de sua pintura: "minha pintura é feita por mim, que estou no mundo, e por quem a observa e que está no mundo também. Eu não vejo, então, porque eu passaria pelo desvio de uma representação ${ }^{31 " .}$. Constituinte do espetacular que tende a representar não mais as realidades do mundo exterior, mas realidades psíquicas, o blecaute confere à cena a dimensão de um espaço mental, sobre o qual se projetam todas as partes da sombra, estéticas e metafóricas.

O blecaute é, então, primeiramente, um alicerce essencial sobre o palco, e é por isso que a Cia 14:20 fez construir uma caixa preta completamente autônoma e móvel chamada Monolithe. Seu aspecto exterior é o de uma caixa retangular ( $8 \mathrm{~m}$ x $12 \mathrm{~m} \mathrm{x}$ $7,70 \mathrm{~m}$ ), laqueada em preto brilhante. Autoportante, ela é montada sobre 73 pés reguláveis, apoiados sobre calços de madeira. No interior, o Monolithe é um teatro com 84 lugares, totalmente equipado tecnicamente. O Monolithe oferece à companhia uma total independência para assegurar as condições necessárias aos seus espetáculos de magia, a saber, um blecaute total. Os espectadores que se dirigem ao Monolithe são inicialmente recebidos e condicionados pela arquitetura e pelo visual do

\footnotetext{
${ }^{28}$ The willing suspension of disbelief, théorie de Samuel Taylor Coleridge publicado em sua Biographia Literaria em 1817 como corolário à fé poética. Se trata aqui de uma adaptação contemporânea de uma formula que não tem nada a ver, originalmente, com o espetacular.

${ }_{29} \mathrm{O}$ que Valentine Losseau, antropóloga e dramaturga da Cia $14: 20$, estudou através dos preconceitos cognitivos, http://www.artefake.com/Valentine-LOSSEAU. $\underline{\text { html }}$

${ }^{30}$ Clément ROSSET, L'invisible, Editions de minuit, 2012, p.10

${ }^{31}$ P. SOULAGES op. cit. p. 16
} 
Monolithe: a caixa preta incorpora ao mesmo tempo o apelo espetacular secular por seu aspecto brilhante, o convite à uma experiência estética (estar fechado em uma caixa no escuro), como no tempo dos espetáculo óticos, e a neutralidade contemporânea de uma promessa de início. O Monolithe, em toda sua dimensão hierática e arcaica, incorpora a riqueza dessa complexidade espetacular.

O blecaute, convidado para os palcos da Magie Nouvelle, oferece, então, um espaço propício para revelar as aparições mais irreais. O ambiente cênico no blecaute estimula particularmente o princípio perceptivo das perturbações visuais. De alicerce inicial, o blecaute passa a ser um componente da cena e participa da escritura cênica própria às reconstituições cognitivas e ao trabalho do cérebro, que são feitos por meio do ritmo cênico, na alternância entre visibilidade e invisibilidade, e nos fenômenos de aparições e desaparecimentos inesperados, como em Ellipses. O blecaute, recentemente bastante utilizado nos espetáculos, se tornou atualmente uma ferramenta dramatúrgica, um componente dramático e uma característica estética. Nesses espetáculos, o artista criador exerce a função de representar o invisível em uma relação global para o espectador para além dos limites fornecidos por uma determinada cultura do real. Por meio da experiência sensorial do blecaute invisível e unificador, o espectador mergulha em um universo irracional e cativante. Ele compartilha o mesmo real modificado que o artista ou que os indivíduos no palco. A ausência da tela ou da quarta parede cria uma união para além da separação palco-plateia. Segundo Clément Debailleuil, o princípio mágico não repousa mais sobre efeitos, mas sobre a experiência, sobre uma recepção espetacular que dá provas de um sentimento mágico. Concretamente, são os corpos em cena (humanos ou não, bolas, plástico, água-viva...), liberados das limitações do real, que provocam o encontro com o sentimento mágico. Se assiste a um deslocamento do visível para uma interiorização: para além do visível, o espectador realiza a experiência do visual. Porque o blecaute possui as qualidades da imagem aberta, da qual Georges Didi-Huberman dá as características no trabalho lhe dedica ${ }^{32}$. Distinguindo o visual do visível, ele alerta para os danos da tirania do visível que faz tela ${ }^{33}$ ao visual ${ }^{34}$. Bem entendido que o visual pertence ao espectador, livre para projetar na imagem uma incorporação que lhe é própria, transformando assim a opacidade da tela do visível de forma positiva. O visual, carregado do sensível, carrega a densidade e a profundidade humana, enquanto que o visível é uma imitação desencarnada. A imagem aberta é, portanto, inseparável da incorporação da qual ela é portadora. Aberta aos sentidos (sensações) do espectador, ela o é também ao sentido (significado). O universo cênico dos espetáculos que literalmente banham o espectador no blecaute tem o poder evocativo da imagem aberta (Georges Didi-Huberman), visto que o blecaute imersivo tem a faculdade de transformar a opacidade da tela do visível até adquirir as qualidades do visual, permitindo que o espectador projete nela seu imaginário.

O blecaute convida o espectador a ultrapassar o visível para entrar nas profun-

\footnotetext{
32 Georges DIDI-HUBERMAN, L'image ouverte, Motifs de l'incarnation dans les arts visuels, Paris, Gallimard, 2007.

${ }^{33}$ No sentido de obstrução, de opacidade. (Nota da tradutora)

${ }^{34}$ Georges DIDI-HUBERMAN, Devant l'image, Les Éditions de Minuit, 1990, p.64.
} 
dezas do visual, a viver uma experiência interior ${ }^{35}$, provavelmente não muito longe do maravilhamento próprio à magia. Para o artista em cena, a experiência do real transformado também passa pela prova do blecaute. Para Aragorn Boulanger, que fez do blecaute uma de suas características estéticas de dançarino, em especial no espetáculo Ellipses, estar no blecaute é um novo estado a dominar. Este espetáculo repousa em uma alternância de blecaute e de luz que constrói uma dramaturgia do desaparecimento no contexto do Cabaret magique da companhia 14:20. Em Ellipses, o blecaute é um componente dramático da mesma categoria que o movimento, o tempo, o espaço e a luz. O blecaute cria um novo espaço-tempo ligado à questão do desaparecimento que marca seu trabalho. O paradoxo desse lapso de tempo no escuro, segundo Aragorn Boulanger, é "que não somos vistos, mas portanto somos olhados $^{36 ", ~ o ~ q u e ~ i n d u z ~ u m a ~ c o n t i n u i d a d e ~ d o ~ g e s t o ~ e ~ d o ~ e s t a d o ~ n o ~ q u a l ~ o ~ d a n c ̧ a r i n o ~}$ se coloca. Em Elipses, o corpo é como que arrancado das leis da física, que são modificadas, em um tempo e um espaço redesenhados pelas luzes, das quais o blecaute é um componente. O personagem-dançarino, em um deslocamento e um gestual hiperlento, leva o espectador ao limiar da realidade e do sonho. O blecaute não é mais um obstáculo, mas permite, ao contrário, criar um espaço onde as referências reais e irreais se tornam difusas, ou até mesmo inúteis: apenas seu próprio corpo é uma referência para qualquer movimento, deslocamento, lentidão, aceleração em um real deturpado de suas impressões iniciais. Do visível ao visual, o blecaute nos espetáculos da Magie Nouvelle tem o poder de desviar a realidade, operando com as falhas, os problemas e as incertezas próprias ao sentimento mágico.

Recebido em: 01/11/2019

Aprovado em: 13/11/2019

\footnotetext{
${ }_{35}$ Georges DIDI-HUBERMAN, L'image ouverte, op.cit., p.25.

${ }^{36}$ Aragon Boulanger, entrevista com Véronique Perruchon em 28 maio 2015 em Lille (França).
} 